\title{
LXII. On the electrical resistance of bismuth to alternating currents in a magnetic field
}

\section{George C. Simpson B.Sc.}

To cite this article: George C. Simpson B.Sc. (1902) LXII. On the electrical resistance of bismuth to alternating currents in a magnetic field, Philosophical Magazine Series 6, 4:23, 554-560

To link to this article: http://dx.doi.org/10.1080/14786440209462879

曲 Published online: 15 Apr 2009.

Submit your article to this journal $\square$

Q View related articles $\square$

Citing articles: 3 View citing articles 5 
sides of the bath by means of a cathetometer. The readings thus obtained, together with the known coefficients of expansion of glass and mercury, furnish the requisite data for determining the amount of metal volatilized. A partial series of the results obtained is given in Table II., together with the results calculated from the observed tensions of mercury-vapour as given by Regnault and Hertz; a more complete set of readings will be published later.

In conclusion I desire to express my thanks to Professor Michelson for the encouragement and helpful criticism given throughont the work, and also to Dr. Gale for the assistance so kindly rendered in the work on the density of mercuryvapour.

Ryerson Physical Laboratory, March 25, 1902 .

LXII. On the Electrical Resistance of Bismuth to Alternating Currents in a Magnetic Field. By George C. SIMPsun, B.Sc., Fellow of the Victoria University*.

TN a previous paper (Phil. Mag. 1901, ii. p. 300) I described 1 experiments which showed that the anomalous effect produced in a bismuth wire carrying an alternating current placed perpendicular to a strong magnetic field can be conveniently represented by an E.M.F. (called the "bismuth E.M.F.") set up in the bismuth itself. It was then found that this bismuth E.M.F. varies in phase and magnitude with different frequencies of alternating current used-the phase being $100^{\circ} 13^{\prime}$ behind the applied E.M.F. with a frequency of 3 per second, the lag increasing to $126^{\circ} 31^{\prime}$ with a frequency of 60 per sec.; the magnitude being a linear function of the frequency and increasing with it.

This investigation having given the variations of the bismuth E.M.F. with frequency, the field being kept constant, experiments have since been made to find how the bismuth E.M.F. varies with the field-strength for a given frequency. The investigation again consisted of two partsdeterminations of the changes in the angle of lag and in the magnitude.

1. The determination of the variation of the angle of lag with different field-strengths, the frequency being constant, was made by the same method as that already used and described in the previous paper. The experiments were now more difficult owing to the diminution of the whole effect due to decreasing

* Communicated by the Author. 
the field-strength, the maximum field at my disposal having been employed in the previous experiments.

Three sets of experiments were made having frequencies of 30,20 , and $13 \cdot 3$ per sec., and in each set three different field-strengths were used. The results of these experiments plotted according to the theory given in the previous paper are shown in figs. 1, 2, and 3. In these figs. the points

Fig. 1.

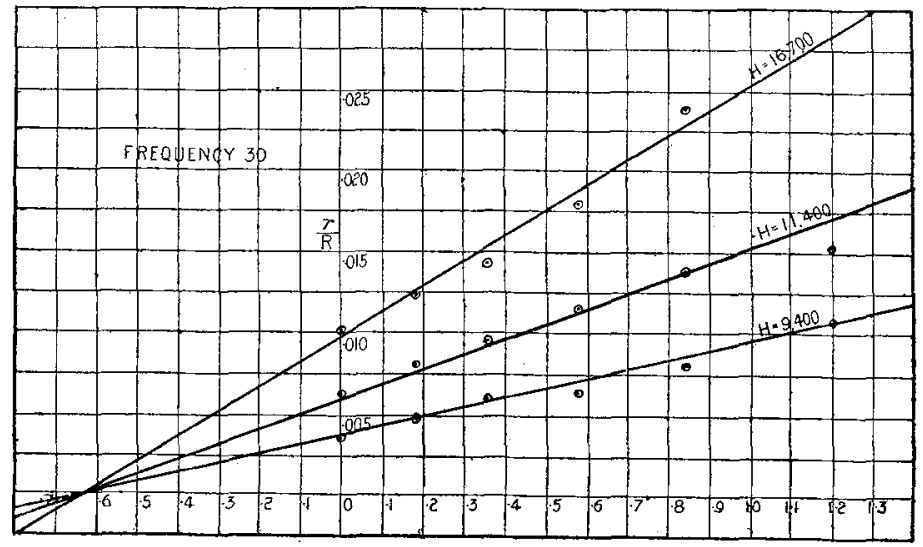

Fig. 2.

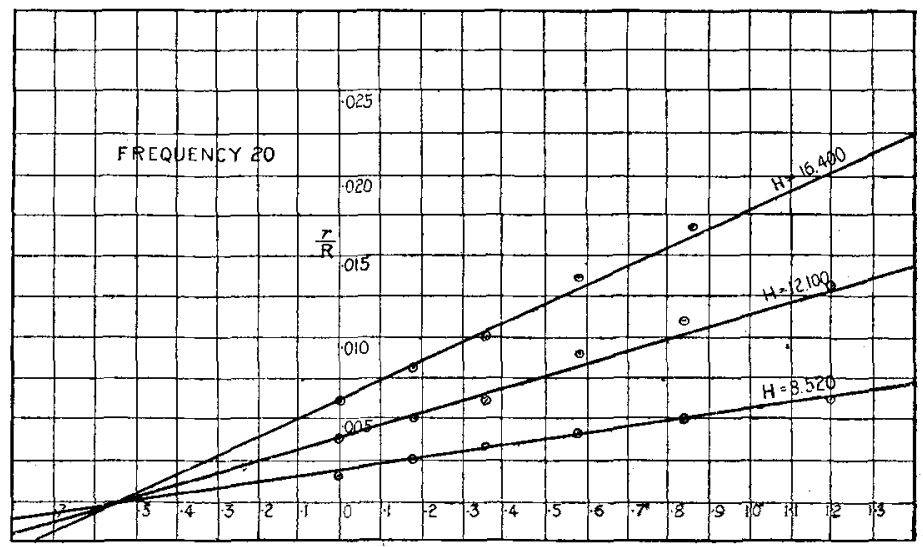

where the straight lines cut the abscissa give the cotangents of the angles of lag. In each of the figs. the straight lines for the different field-strengths cut the abscissa in the same point; hence the experiments show that the angle of lag is 202 
independent of field-strength. Thus the curve already given connecting angle of lag with frequency holds for all tields trengths.

Fig. 3.

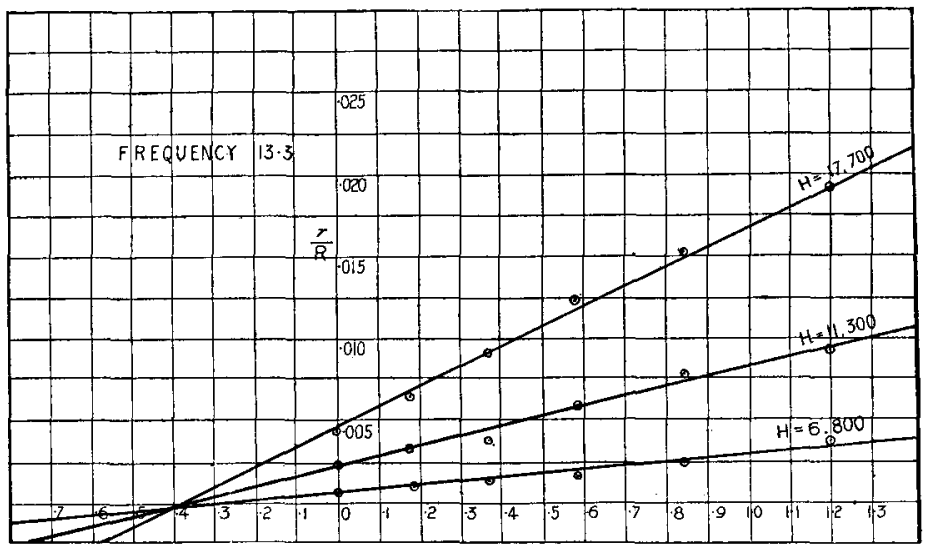

II. The variation of the magnitude of the bismuth E.M.F. with different field-strengths, frequency constant, was calculated from the results obtained in the above determination.

These results, with a few more from separate experiments,

Fig. 4.

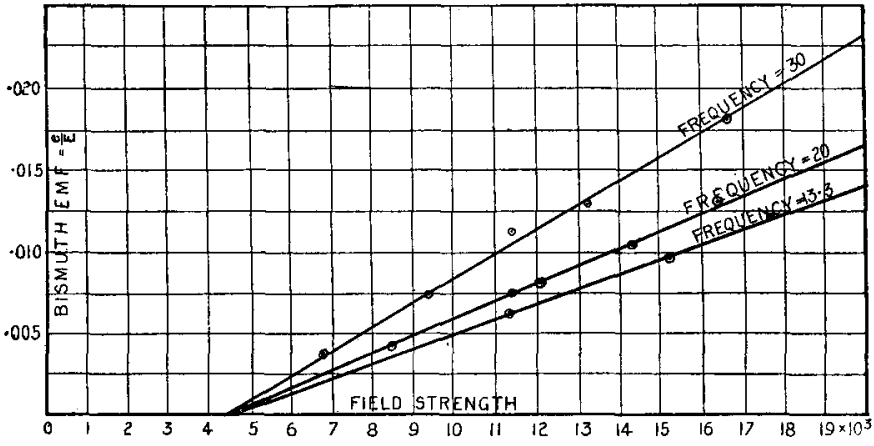

are plotted in fig. 4 , in which the value of the bismuth E.M.F. $\frac{e}{\mathrm{E}}$, is plotted against, field-strength. The conclusions to be drawn from this fig. are very interesting, showing as they do: 1st, that the magnitude of the bismuth E.M.F. is a linear function of the field-strength ; 2nd, that the bismuth E.M.F. is zero at the same field-strength for all frequencies; and 
$3 \mathrm{rd}$, that this field-strength is considerable-4500 lines per sq. cm. This latter result is also interesting from the fact that Lenard and others, using very high frequencies, bave found a negative effect in no field; with the low frequencies used in my experiments the negative effect can just be detected, but could not be satisfactorily measured.

\section{Temperature Variations.}

Experiments were next undertaken to find the effect of temperature variations on the bismuth E.M.F.

In all the previous experiments a Hartmann \& Braun bismuth spiral, designed for field-testing, had been used, but this became useless when experiments were made at other than atmospheric temperatures, so it was replaced by a wire $-3 \mathrm{~mm}$. in diameter and about $10 \mathrm{~cm}$. long, bent into the form

Fig. 5.

of a flat grid and soldered to two thick copper wires (fig. 5). These grids were very easily broken, and a number were used during the experiments; the bismuth wire was supplied by Messrs. Hartmann \& Braun.

For temperatures above atmospheric a grid was placed in a glass vessel (fig. 6) consisting of an inner vessel having a

Fig. 6.

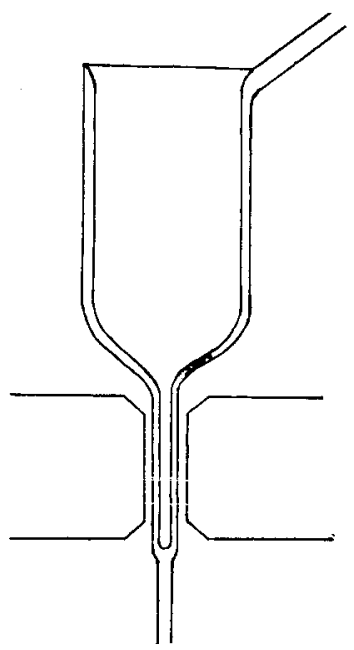

flat tube joined on at the bottom, into which the bismuth wire projected, surrounded by a similar slightly larger vessel. 
In the space between the two, water from a thermostat circulated, so keeping the bismuth (placed in oil) at the required temperature.

For temperatures below atmospheric a similar vessel was used, except that the space between the two walls was evacuated, and. different freezing-mixtures placed in the inner vessel.

Low temperatures were obtained as follows:-Liquid air gave a constant temperature of $-185^{\circ}$, a mixture of solid $\mathrm{CO}_{2}$ and acetone gave $-70^{\circ}$, while $-95^{\circ}$ was obtained by bubbling air through this mixture; solid $\mathrm{CO}_{2}$ in alcohol produced $-40^{\circ}$.

The bismuth wire having a very low resistance (about $2 \mathrm{ohms}$ at $17^{\circ}$ ) and the field being comparatively weak, owing to the large separation of the pole-pieces necessitated by the glass vessel, the whole effect to be measured was extremely small, so that it was found convenient to work only with the strongest field to be obtained under the conditions (about 7000 lines) and with a frequency of 30 per sec. With this field and frequency complete experiments were made at $-185^{\circ},-70^{\circ},-40^{\circ}, 0^{\circ}, 17^{\circ}, 43^{\circ}, 68^{\circ}$, and $100^{\circ}$, the results of which are given in fig. 7. In this figure it will be seen

Fig. 7.

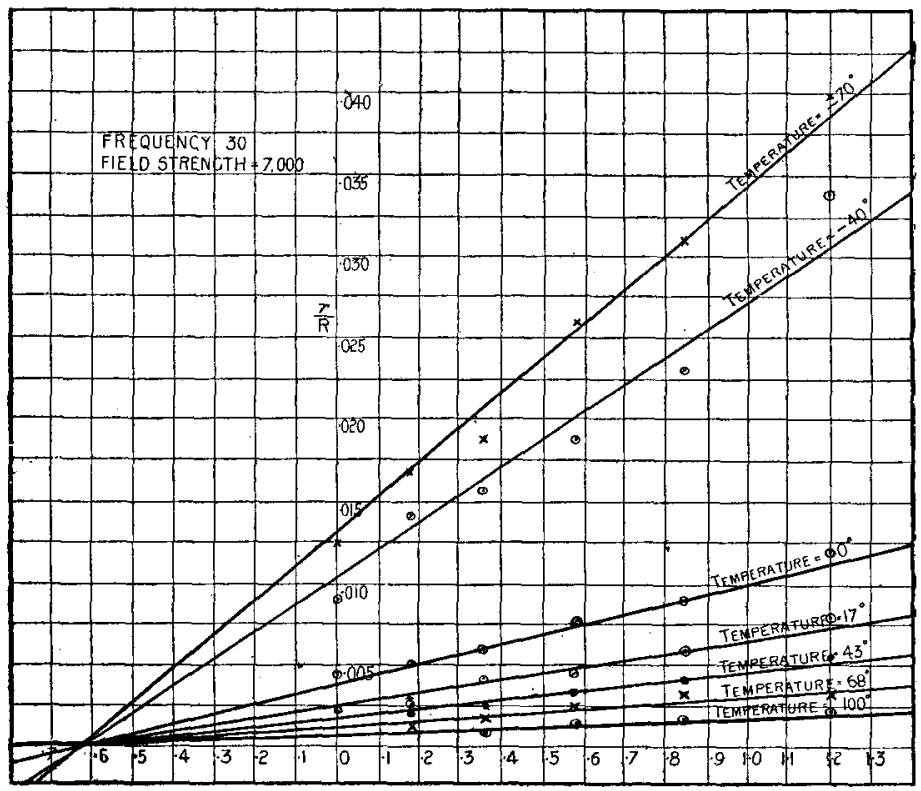

that the lines all cross the abscissa in the same point, hence the angle of lag is independent of temperature. 
As the angle of lag has already been found to be independent of field-strength, it may now be safely said that the angle of lag is a function of the frequency only.

To find the relation between the magnitude of the bismuth E.M.F. and temperature, the results given in fig. 7 were used; but besides these it was found possible to get a measurement of the magnitude only, every $10^{\circ}$ between $-90^{\circ}$ and $0^{\circ}$, by making use of the fact, just found, that the angle of lag is independent of temperature.

Fig. 8 gives the results of these experiments, and shows

Fig. 8.

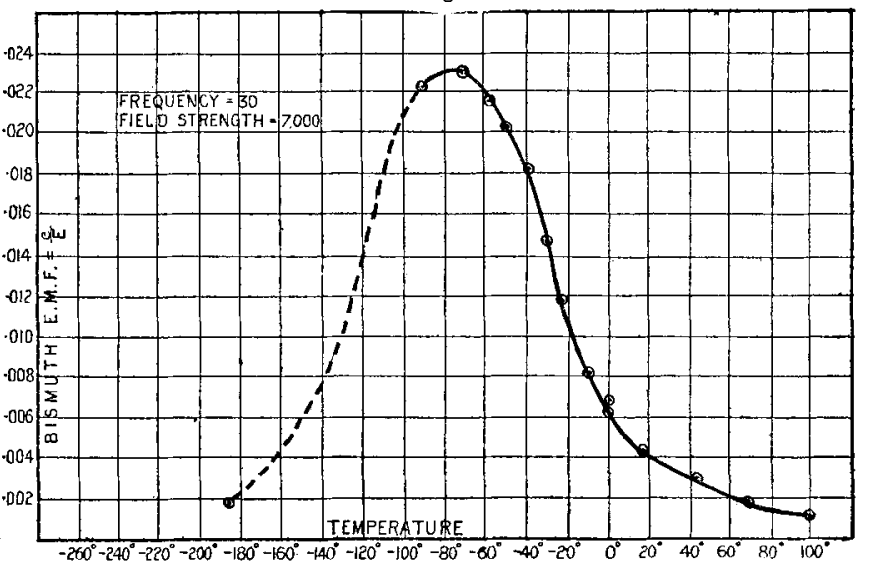

that the effect, which is small at $-180^{\circ}$ and $100^{\circ}$, becomes comparatively large between, reaching a maximum at $-70^{\circ}$, where with the small field of 7000 lines and a frequency of 30 per sec. the bismuth E.M.F. is $2 \cdot 2$ per cent. of the E.M.F. applied to the bismuth, being five times greater than its value at ordinary temperatures.

This variation of the bismuth E.M.F. with temperature is most important, because it shows that the effect, if not due to the Hall effect, has a close connexion with it, for a very similar variation of the Hall effect with temperature has been demonstrated by Dr. A. Lebret ('The Electrician', vol. xxxvi. 1896, p. 785).

In conclusion the results of the whole investigation may be briefly stated :-

I. The magnitude of the bismuth E.M.F.

(a) is proportional to the current in the bismath;

(b) is a linear function of the field-strength;

(c) increases with the frequency;

(d) varies with temperature, having a maximum value about $-70^{\circ}$, decreasing rapidly on either side. 
At ordinary temperatures its value is given by

$$
\frac{e}{\mathrm{E}}=(3 \check{5}+3 \cdot 9 n)(\mathrm{H}-4500) 10^{-8},
$$

where $n=$ frequency, and $\mathrm{H}=$ field-strength.

II. The angle of lag of the bismuth E.M.F. behind the current in the bismuth

(a) varies with frequency;

$(b)$ is independent of temperature and field-strength.

Owens College, Manchester.

LXIII. On Radiation of Heat and Light from Heated Solia Bodies. By J. T. BoT'OMLeY, D.Sc., F.R.S.*

[Plates V. \& VI.]

THE following paper describes a further instalment of 1 experiments on radiation of beat and light from heated solid bodies, a subject to which I have given attention for a considerable number of years. It is a difficult subject, and it has only been at times that I have been able to make progress in the prosecution of the inquiry. I have treated it from first to last in a purely experimental way. I do not feel that there exists at present suflicient experimental information to admit of anything like a complete theory. Indeed the information which we possess is of the scantiest character.

My aim has been to determine directly the quantity of heat lost from a given surface under given conditions; and the method by which I have carried out my experiments bas heen to put the radiating body into a vacuum as complete as I can obtain, and then to measure the energy lost from it in a Fiven time, noting the circumstances. By adopting this plan $I$ avoid determinations of the value of heat-receptors, such as sooted bolometers or sooted thermojunctions; and I obtain results in absolute measure.

In a paper published in the Transactions of the Royal Society as far back as 1887 I showed that it is possible to obtain with the Sprengel-pump a vacuum so good that the effect of convection on loss of heat from a hot body, in so far as that loss is caused by non-condensable gases, ceases to be of importance in comparison with loss due to pure radiation; in fact, that increasing the vacuum, as

* Communicated by Lord Kelvin. 